Territorios 30 / Bogotá, 2014, pp. 91-108

ISSN: 0123-8418

ISSNe: 2215-7484

Reconfiguración territorial y mercados de tierras rurales

\title{
Mercado de tierras en un ejido mexicano: El caso de Campos, en Manzanillo, Colima, 1994-2013
}

Land Market in a Mexican Ejido: The Case of Campos, in Manzanillo, Colima, 1994-2013

Mercado de terras em um exido mexicano: o caso de campos, em Manzanillo, Colima, 1994-2013

Francisco Javier Verduzco Miramón ${ }^{\star}$

J. Luis Seefoó Luján ${ }^{\star \star}$

Recibido: 17 de enero de 2014

Aprobado: 14 de marzo de 2014

Doi: dx.doi.org/10.12804/territ30.2014.04

Para citar este artículo:

Verduzco, F. J. y Seefoó J. L. (2014). Mercado de tierras en un ejido mexicano: el caso de Campos, en Manzanillo, Colima, 1994-2013. Territorios, 30, 91-108. doi: dx.doi.org/10.12804/territ30.2014.04

* Licenciado en Ciencia Ambiental y Gestión de Riesgos por la Universidad de Colima. Maestro en Ciencias Sociales especialidad en Estudios Ruralespor El Colegio de Michoacán, A. C. Actualmente es estudiante doctoral en el programa antes mencionado. Estudiante becario por el Conacyt en el Programa Integrado de Ciencias Sociales del Centro de Estudios Rurales en El Colegio de Michoacán. Egresado de la Licenciatura en Ciencia Ambientaly Gestión de Riesgos por la Universidad de Colima. Correo electrónico: socio100_@hotmail. com; verduzcomf@colmich. edu.mx

* * Profesor investigador del Centro de Estudios Rurales. El Colegio de Michoacán A.C. Doctoren Ciencias So- $\Rightarrow$ 
Palabras clave

Politicas neoliberales, mercado de tierras,

desarrollo energético y portuario, Manzanillo, México.

Keywords

Neoliberal policies, land market, energy, port development, Manzanillo, Mexico.

Palavras-chave

Politicas neoliberais, mercado de terras, desenvolvimento energético e portuário, Manzanillo, México.

\section{territarias 30}

\section{RESUMEN}

La reforma al artículo 27 constitucional de 1992 convirtió a los ejidatarios en propietarios de la tierra que trabajaban, condición reforzada por el Programa de Certificación de Derechos Ejidales (Procede) que, en 1994, les otorgó títulos parcelarios y de propiedad. De manera colateral, con estas políticas neoliberales se dinamizó el mercado de tierras y, con ello, se facilitó la inversión nacional y extranjera en el territorio mexicano. En el caso de Manzanillo, particularmente en el ejido de Campos, se instaló una planta de almacenamiento y distribución de gas licuado de petróleo y otra de tratamiento de gas natural licuado, más un gasoducto que conecta a la ciudad portuaria con Guadalajara, Jalisco.

El objetivo principal de este artículo, es mostrar cómo las reformas constitucionales decretadas hace poco más de dos décadas, en conjunto con factores globales y locales, en la actualidad han intensificado el mercado de tierras en el ejido de Campos, facilitando - aún más - la inversión capitalista ya existente. La información que se presenta en la investigación se obtuvo principalmente de las entrevistas con algunos ejidatarios de Campos, como resultado de trabajo etnográfico realizado en distintos momentos por ambos autores desde el año 2011 hasta 2013.

\section{ABSTRACT}

The reform to Article 27 of the Constitution in 1992 offered Mexico's ejidatarios the opportunity to become owners of the land they cultivated, while the Programa de Certificación de Derechos Ejidales (Certification Program for Ejidal Rights, or Procede), instituted in 1994, awarded them titles to their fields as legitimate private property. One collateral effect of these neoliberal policies was to stimulate the land market that, in turn, facilitated national and foreign investment in Mexican territory. In the case of the port of Manzanillo (Colima) and, more specifically, the Ejido de Campos, those changes led to the construction of a liquefied petroleum gas storage and distribution plant, and a second facility for processing liquefied natural gas. In addition, a pipeline was built to connect this port city to Guadalajara, Jalisco.

In light of these transformations, the main objective of this article is to show how the constitutional reforms enacted over two decades, along with a series of factors both global and local in nature, have intensified the land market in the Ejido de Campos, and stimulated additional capitalist investment. The information presented in the research was obtained primarily from interviews with local ejidatarios conducted as part of the ethnographic research carried out periodically by the two authors from 2011 to 2013 .

\section{RESUMO}

A reforma ao artículo 27 constitucional de 1992 converteram aos ejidatários em proprietários da terra que trabalhavam, uma condição reforçada pelo Programa de Certificação de Direitos Ejidais (Procede) que em 1994, lhes outorgou títulos de terras e de propriedade. De forma colateral, com estas políticas neoliberais dinamizou-se o mercado de terras e, com isso, se facilitou a inversão nacional e estrangeira no território mexicano. No caso de Manzanillo, particularmente no exido de Campos, instalou-se uma planta de armazenamento e distribuição de GLP (gás liquefeito de petró- 
leo) e outra de tratamento de GNL (gás natural liquefeito), mais um gasoduto que conecta à cidade portuária com Guadalajara, Jalisco.

O objetivo principal deste artigo é mostrar como as reformas constitucionais decretadas há pouco mais de duas décadas, em conjunto com fatores globais e locais, na atualidade têm intensificado o mercado de terras no exido de Campos, facilitando ainda mais, a inversão capitalista já existente. A informação que se apresenta na pesquisa obteve-se principalmente das entrevistas com alguns ejidatários de Campos, como resultado de trabalho etnográfico realizado em diferentes momentos por ambos os autores desde o ano 2011 até o ano 2013.

\section{Introducción}

La apertura comercial puesta en marcha con el Tratado de Libre Comercio de América del Norte (TLCAN), firmado por México en 1994, resultó un factor importante que facilitó la inversión extranjera en el territorio mexicano, un ejemplo de esto es la costa de Manzanillo. Además, la reforma al artículo 27 constitucional de 1992 y el Programa de Certificación de Derechos Ejidales (Procede), que entró en vigor en 1994, 'legalizaron' la compra-venta de tierras ejidales.

En nuestro caso de estudio, la mayor parte del suelo agrícola fue usado para la construcción de los proyectos gaseros que requerían grandes porciones de tierra. Y, como consecuencia, se deforestó y contaminó el entorno natural, lo que impactó en las fuentes de empleo agrícolas de la población. De esta forma, los ejidos de Campos, El Colomo y La Arena, Jalipa, Tapeixtles, Salagua, Colonia del Pacífico, Abelardo Rodríguez y Miramar, se enlazaron de manera directa a la economía global y siendo parte del hinterland de Manzanillo, 'tuvieron el privilegio' de acompañar al desarro- llo industrial, como parte de la estrategia mercantil tanto nacional, como mundial.

La problemática de nuestra investigación se centra en el crecimiento - ya existente- de inversión capitalista nacional y transnacional en el ejido de Campos, después de la reforma al artículo 27 constitucional y el Procede aplicados a nivel nacional, en conjunto con otros factores locales, como los cambios en el uso del suelo y la persuasión entre organizaciones y líderes ejidales para rentar y traspasar el dominio sobre la tierra. Así, nuestro objetivo es explicar cómo las reformas políticas decretadas hace más de 20 años, combinadas con otros factores, han intensificado el mercado de tierras en el ejido de Campos, Manzanillo, Colima.

El presente artículo se deriva del proyecto de investigación elaborado como parte de la tesis de maestría titulada: La Manzanillo, Colima tras el desarrollo energético y portuario, 1970-2013. La estrategia metodológica consta de cuatro herramientas aplicadas en distintos momentos a lo largo de los últimos dos años: 1) las entrevistas a profundidad; 2 ) el trabajo etnográfico; transformación del espacio rural en Campos, ciales por la Universidad de Guadalajara. Correo electrónico: jlseefoó@hotmail.com; seefoo@colmich. edu.mx territarias 30

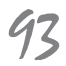


3) el Plan de Desarrollo Metropolitano de Manzanillo de 1975; y 4) las fotografías.

Con las entrevistas a distintos actores clave - ejidatarios y funcionarios públicos locales - y el trabajo etnográfico, se logró construir y describir el proceso de mercantilización de las tierras ejidales, así como identificar algunos personajes clave y su participación en el entramado. El Plan de Desarrollo Municipal de 1975 nos permitió identificar cómo y hacia dónde se proyectó el crecimiento industrial en el territorio manzanillense y, en espacial, los cambios en el uso del suelo agrícola previstos en el ejido de Campos. Finalmente, con las fotografías captamos el escenario capitalista observado durante la estancia de trabajo de campo.

La estructura capitular consta de tres apartados. En el primero se describe el proceso de desarrollo capitalista que ha tenido lugar desde principios del siglo $\mathrm{XX}$ en la ciudad y puerto de Manzanillo, Colima. A partir de la noción de planificación, se enfatiza en la zonificación del suelo y en cómo esta priorizó la asignación de espacios para el desarrollo de actividades como la minería, la portuaria, el turismo y la industria energética, en detrimento de la agricultura. Ya en la práctica, dicha noción respaldó los cambios en el uso del suelo. El segundo, parte de las políticas neoliberales aplicadas por el Estado mexicano durante la primera mitad de la década de los noventa, y sus implicaciones en el ejido y los ejidatarios. Nos referimos a la reforma al artículo 27 constitucional de 1992 y el Procede, en 1994. En el tercero se describe el intenso mercado de tierras ejidales en el municipio, centrándonos en el caso específico de Campos. En un primer momento, la compra-venta se presentó al interior del ejido y, en un segundo, al exterior.

\section{La ciudad y puerto de Manzanillo}

Echando una mirada hacia el pasado, desde principios del siglo XX, el puerto colimense fue parte fundamental del proyecto modernizador de Porfirio Díaz. Con financiamiento norteamericano, el ferrocarril fue inaugurado el 12 de diciembre de 1908, conectando con el centro del país para atender el comercio marítimo que demandaba México (Ezquerra, 2006). Desde entonces, la visión capitalista ha estado presente en este lugar, cada vez con mayor alcance.

Por su posición geográfica a nivel nacional (ver mapa 1), Manzanillo ha sido un laboratorio para la aplicación de programas piloto derivados de las políticas de crecimiento y desarrollo mundial. Uno de estos, La marcha hacia el mar, prioritario durante el sexenio presidencial de Adolfo Ruiz Cortines (1952-1958), buscó consolidar la infraestructura marítima portuaria, con apoyo de una reforma que ayudó a tener un servicio comercial estratégico para intentar mejorar las finanzas del país, bajo un modelo proyeccionista del desarrollo estabilizador (Ezquerra, 2006, p. 61).

Las décadas de los sesenta y setenta del siglo $\mathrm{XX}$ representaron un periodo trascendental para el presente y futuro del territorio manzanillense. En 1961, la empresa Peña Colorada se declaró como el yacimiento mineral más rico de México, con 100 millo- 


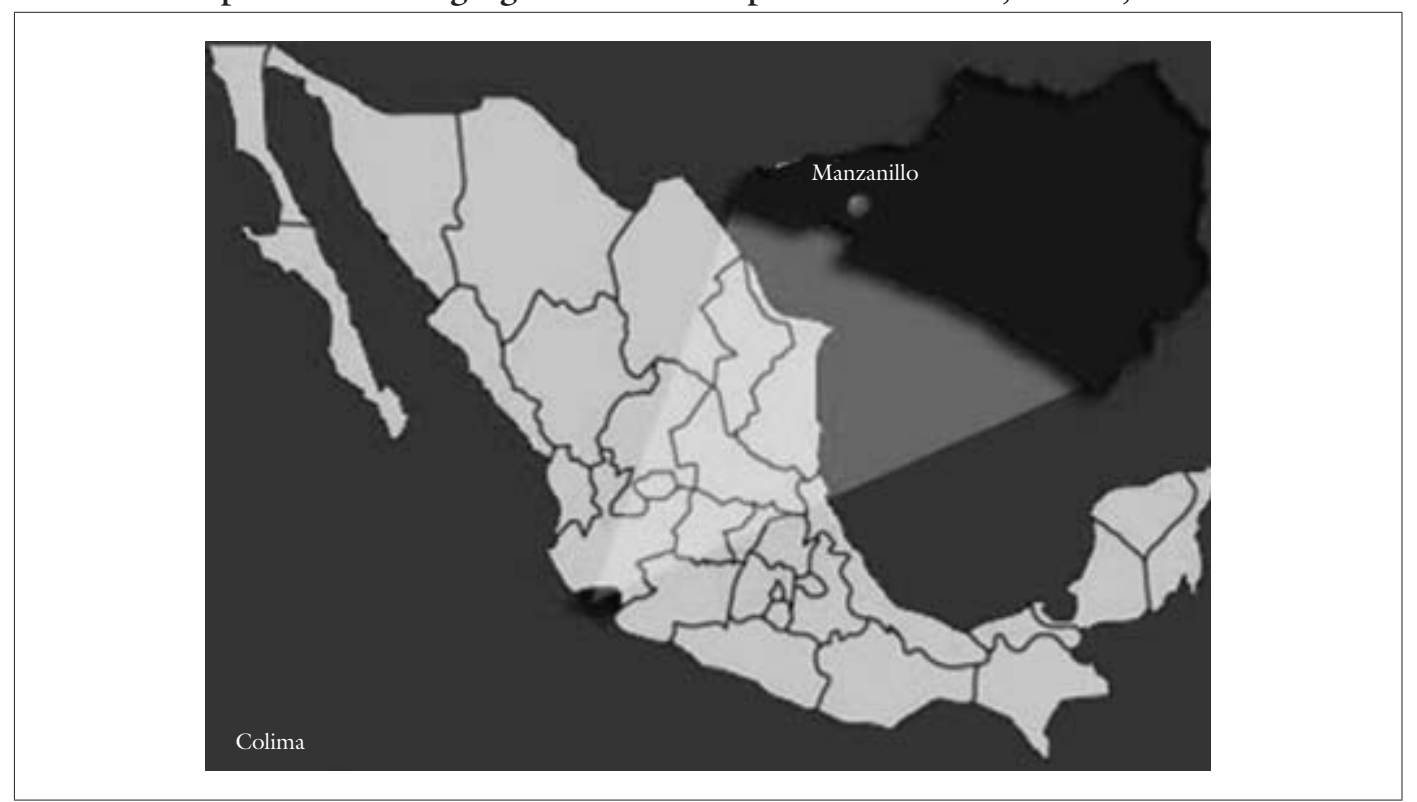

Fuente: www.skyscrapercity.com

nes de toneladas de hierro disponibles para su explotación durante más de un siglo. Su mayor cercanía al puerto de Manzanillo respecto a Lázaro Cárdenas, Michoacán, propició que la costa colimense fuera elegida como el sitio para exportar el material extraído hacia el continente asiático, bajo un proceso colmado de incertidumbre e intereses económicos (Godau, 1982).

Durante el mandato presidencial de Luis Echeverría Álvarez (1970-1976), el 1 de junio de 1970 fue inaugurado el Puerto Interior de San Pedrito y, con ello, el mercado asiático se consolidó en América del Norte (Ezquerra, 2006). De este modo, inició la ruta comercial marítima ampliamente conocida e investigada: la Cuenca del Pacífico, en donde Manzanillo resultó ser pieza clave, ante la saturación del puerto de Long Beach en la costa occidental de Estados Unidos, debido a los costos de traslado entre Asia y Europa, al ser más rentable transportar por mar, usando este puerto y por vía terrestre conectar con Altamira, Tamaulipas, para embarcar hacia el continente europeo.

Con respecto al sector turismo, con la construcción de Las Hadas en 1974, propiedad del boliviano Atenor Patiño, conocido mundialmente como 'el rey del estaño', el territorio manzanillense se transformó en el nuevo atractivo concurrido por viajeros nacionales y extranjeros. Además, el Aeropuerto Internacional Playa de 
Oro, en 1973, se convirtió en un medio de conexión importante con el exterior (Ezquerra, 2006, p. 53).

En esta investigación, el crecimiento en el sector turismo, el portuario y el minero, así como la infraestructura complementaria (viviendas, carreteras, vías férreas, hospitales), las condiciones del medio natural y socioeconómico de la población, determinaron la planificación del territorio manzanillense.

\section{La planificación del territorio manzanillense}

Para referirnos al concepto de planificación nos remitimos a Oren Yiftachel, quien la define como: "La formulación, el contenido y la aplicación de políticas públicas dirigidas por el Estado, encaminadas hacia el desarrollo urbano y regional, partiendo del ordenamiento y la zonificación de los usos del suelo permitidos y no permitidos en un territorio" (1998, p. 398).

En nuestro caso de estudio, la estrategia política de la planificación del territorio manzanillense quedó registrada en el Plan Director de Desarrollo. Así, la actividad minera se proyectó alrededor de la planta peletizadora del Consorcio Peña Colorada y del parque industrial en el ejido de Tapeixtles, colindante con la terminal portuaria para facilitar el transporte del mineral para su exportación. Por su ubicación, fácil acceso al ferrocarril y contar con suficientes terrenos planos para su desarrollo, Campos, El Colomo y La Arena y Jalipa fueron destinados para atender la proyección comercial del binterland del puerto de Manzanillo. Además, como medida preventiva al crecimiento del puerto, las lagunas de las Garzas y de Cuyutlán fueron decretadas como reservas territoriales. Para el turismo, se asignó la línea costera que va desde la bahía de Manzanillo hasta el aeropuerto internacional Playa de Oro (Ezquerra, 2006).

$\mathrm{Al}$ sector industrial se destinó suelo plano con fácil acceso al agua, recurso necesario para su desarrollo, así como a los medios de transporte marítimo, férreo y carretero. De esta manera, el ejido de Campos resultó un espacio 'adecuado' para la cimentación de infraestructura de este sector, a pesar de no satisfacer por completo los parámetros requeridos. La primera obra que comenzó a operar fue la central termoeléctrica Manuel Álvarez, en 1978, como parte del Sistema Interconectado Nacional. Su prioridad fue abastecer de energía eléctrica a las operaciones portuarias de Manzanillo, aunque oficialmente se dijo que sería para la población del estado de Colima, ciudades importantes como Guadalajara, Jalisco y la zona industrial del occidente de México (Comisión Federal de Electricidad, s. f.).

Con la instalación de la central termoeléctrica, los efectos comenzaron a presentarse sobre todo en el sector turismo y agrícola. Prácticamente, desde que se construyó la planta, una pluma de humo, formada por óxidos de azufre $\left(\mathrm{SO}_{2}\right)$, óxidos de nitrógeno $\left(\mathrm{NO}_{\mathrm{X}}\right)$, partículas suspendidas, entre otras, sale de sus chimeneas. El problema se agranda ante las condiciones climáticas propias de la costa, ya que la

\section{territarias 30} 96 
humedad en la atmósfera es mayor que el humo contaminado, lo que provoca que este último circule a nivel del suelo y ahí se deposite. Este fenómeno tan común de observar por las mañanas, tuvo consecuencias en otros sectores económicos como el turismo, ya que la infraestructura hotelera se teñía por completo. De esta manera, aquel boom, que vivió Manzanillo en la década de los sesenta y se proyectaba a futuro, se vio frenado.

La agricultura era la principal fuente de ingresos económicos en la zona pero, a decir de los ejidatarios de Campos, el suelo agrícola ha disminuido drásticamente su fertilidad convirtiéndose en un espacio cada vez menos productivo. En el recuerdo de los campesinos está la imagen recreada de 'un vergel agrícola', en donde se producían los mejores frutos de la región. Temporada por temporada, se cosechaba el coco de agua, limón, ciruela, plátano, papaya, mango, piña y marañón que se comercializaban en mercados locales, de todo el estado de Colima y, por medio del ferrocarril, a ciudades importantes de la región occidente como Zapotlán el Grande (ahora Ciudad Guzmán) y Guadalajara, Jalisco.

Armín Núñez Meza, ${ }^{1}$ uno de los líderes campesinos más importantes de los años setenta, quien apoyara en sus inicios el establecimiento de la termoeléctrica, ahora la cuestiona pues el hollín daña las frutas y perjudica la salud de las personas. Él se mudó de domicilio para evitar parte de sus efectos nocivos. El señor Armín comentó en una entrevista que:
(...) el ejido de Campos se caracterizaba por la producción de frutales. Campos no era un terreno agrícolamente hablando para el maíz, se daba muy poco porque la tierra es arenosa, muy delgada, y para el maíz se necesita una tierra un poco más gruesa. Sí, la gente sembraba maíz pero para autoconsumo nada más, para vender no, solo para comer. El que se daba mejor era el ajonjolí, pero lo fuerte antes de que se instalara la termoeléctrica, la regasificadora y todo eso, eran los frutales. Por ejemplo, el coco de agua era la cosa principal. Yo no anduve mucho en la república, anduve por ahí de Guerrero, Tabasco, Veracruz y parte de Jalisco donde había coco y en ninguna parte, con toda seguridad, miré cocos como en Campos de grandes, una producción muy buena. (...) Mi madre vendía en el mercado, entonces nosotros traíamos de Campos fruta como ciruelas, mangos, nances, piñas, cocos, limones, guayabas todo eso se daba en Campos, era como un edén. (...) Una persona que tuviera una huertita chiquita de dos hectáreas en Campos se mantenía de buena manera. Yo conocí a una familia de un señor que se llamaba Guadalupe Virgen, tenía una huertita, yo creo que no eran ni dos hectáreas, se mantenían y tuvieron para mandar a sus hijos a estudiar a Guadalajara (Entrevista del autor a Armín Núñez Meza, Ejido de Campos, Manzanillo, 28 de febrero de 2013).

En particular, los ejidatarios refieren que los efectos a su economía han sido graves, ya que el fruto cosechado y su calidad fue cada vez menor durante las siguientes décadas,
${ }^{1}$ Ejidatario en Campos, El Colomo y La Arena con destacada carrera politica localdurante la década de los sesenta y setenta, dentro de los cargos fue representante ejidal de Campos en tres ocasiones distintas, diputado local en el Congreso del estado de Colima, delegado de la Confederación $\mathrm{Na-}$ cional Campesina (CNC) en la región occidente, secretario de Acción Agraria en la liga de Comunidades Agrariasy, posteriormente, delegado del Partido Revolucionario Institucional (PRI) en Manzanillo.

territarias 30

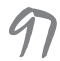


lo que impidió su comercialización más allá del mismo municipio. Ante el escenario catastrófico, para los agricultores propietarios, una forma más eficaz de obtener dinero del campo que ya no producía igual, fue la renta o la venta de sus propiedades.

\section{De la renta y venta 'disfrazadas', al mercado abierto de tierras}

Uno de los elementos que fortaleció la inversión extranjera ya existente en el territorio mexicano fue la adopción del paquete político neoliberal, apoyado y legitimado por el Banco Mundial. Con la firma del Tratado de Libre Comercio en América del Norte (TLCAN) en 1994, y las reformas complementarias, el Estado mexicano abrió más sus puertas al comercio internacional con la promesa de modernizar el sector agrícola y hacerlo competitivo en el mercado internacional. En ese sentido, las modificaciones al artículo 27 constitucional y la aplicación del Procede resultaron dos cartas fundamentales para las intenciones gubernamentales.

\section{La reforma al artículo 27 constitucional}

La reforma agraria posrevolucionaria modificó la estructura de tenencia de la tierra de las haciendas e implantó nuevos tipos de propiedad de la tierra: la social conformada por el ejido y la comunal, y la privada por los pequeños productores. El reparto concedió a los campesinos el medio de subsistencia que demandaban, para con ello combatir la pobreza y la marginalidad social. Los resultados numéricos indican que más de la mitad del territorio nacional fue entregado a tres millones de campesinos, sin embargo, la justicia que se esperaba no llegó (Morett, 2003).

A la vez, esta medida política también fue utilizada como un mecanismo reglamentario impuesto por el Estado para ejercer control sobre ellos. Así, sus integrantes estuvieron sometidos a una legislación que colocó candados y obstáculos para acceder al dominio pleno y un formato de organización en el que desde las convocatorias hasta el reconocimiento formal de la elección de los comisariados estaba sujeto al visto bueno del gobierno a través de la Secretaría de la Reforma Agraria (SRA). De la misma manera, importantes decisiones relacionadas con la explotación del ejido también eran reguladas por la autoridad gubernamental (Morett, 2003, p. 13).

La década de los noventa marcó un antes y un después en el sector agrario mexicano. La crisis económica en el campo seguía, la apertura comercial para hacerlo competitivo en el exterior resultó una nueva forma de intervención política del Estado. Con los cambios al artículo 27 constitucional en 1992, se dio por terminado el reparto y marcó el inicio de una etapa distinta en la organización de la propiedad. La ley agraria priorizó dos ejes: el primero se trató de un conjunto de transformaciones para el fortalecimiento de la propiedad social, sin embargo su puesta en marcha tendió más hacia la desaparición de la tierra ejidal y la comunal. El segundo fue una serie de me- 
didas para intentar garantizar la seguridad de los propietarios sobre sus medios de subsistencia y, a largo plazo, buscar la formación de la 'mediana propiedad' (Morett, 2003, p. 16).

En la reforma agraria, una pequeña propiedad podía considerar hasta 100 hectáreas de riego, 200 de temporal, 300 de cafetal y 800 de bosque, y se restringían los cambios en el uso del suelo. Con la nueva ley (1992) se permitió convertir los predios ganaderos en agrícolas y en este tipo de tenencia se incrementaron sus límites agrícolas hasta 25 veces más, así como sus posibilidades de asociación hasta con 25 miembros. Mientras que las modificaciones legislativas solo permitieron 10 hectáreas de riego, 20 de temporal y 40 de agostadero para la propiedad ejidal y comunal (Toledo, 1994). Por lo tanto, para fines agrícolas una sociedad puede poseer desde 2500 hasta un máximo de 7500 hectáreas dependiendo del cultivo y la calidad del suelo. Esta condición legal ha sido determinante para conformar unidades de producción con dimensiones mayores y con esto reducir la participación de la propiedad social, sea por renta o por otros mecanismos de usufructo de la tierra.

Antes de las modificaciones al artículo 27 constitucional fechadas en 1992, la propiedad social era una forma incompleta de la privada, dado que legalmente los ejidatarios y comuneros recibieron los derechos para hacer uso y gozar de los productos obtenidos de sus parcelas, pero no pudieron hacer valer sus derechos al no contar con el dominio pleno. En realidad no eran más que usufructuarios de un medio que no les pertenecía, ya que la enajenación de las propiedades estaba sometida a la decisión presidencial. Por lo tanto, estaban obligados a permanecer sujetos a una serie de restricciones y limitaciones: prohibida su renta, venta o usarla como garantía para obtener un crédito y solo podía trasmitirla a un miembro de su familia - cónyuge o hijo- o a otra persona. En caso de incumplir alguna de las demandas perdían su condición (Concheiro y Diego, 2003).

Entre otras cosas, con los cambios al artículo 27 constitucional los ejidatarios y comuneros se convirtieron en propietarios de la tierra y con ello obtuvieron la autorización para la venta, la renta, la herencia y la hipoteca de sus tierras (Concheiro y Diego, 2003 , p. 184). De esta manera, el marco legislativo se mostró flexible al quitar los candados y obstáculos que colocó la reforma agraria hacia la protección de la propiedad, pero descuidó la producción. Por lo tanto, la estrategia política que retuvo de manera obligada la fuerza de trabajo campesina y garantizó la unidad ejidal y comunal, terminó por disminuir la producción, estimular la venta de terrenos a precios bajos e incluso la migración de los agricultores. Mientras que para los empresarios agrícolas se convirtió en un apoyo para la especulación inmobiliaria y para orientar la tierra a usos no agropecuarios.

\section{El Procede}

De manera paralela a la reforma de 1992, el Programa de Certificación de Derechos Eji- territarias 30

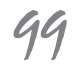


dales y Titulación de Solares Urbanos (Procede) comenzó a operar en 1994. Según el discurso oficial, se trató de un proceso legal, voluntario y gratuito para otorgar certeza jurídica a los posesionarios de la tierra mediante la delimitación parcelaria y entrega de certificados y títulos de propiedad para que los ejidatarios, ahora dueños, pudieran vender sus propiedades (Concheiro y Diego, 2003, p. 185).

En total, México tiene 13021 ejidos poseedores de 27807529,71 hectáreas, es decir, el 32,66\% de los 103 millones a nivel nacional que equivalen a más de la mitad del territorio nacional. El estudio elaborado por Zepeda muestra los resultados obtenidos durante los primeros cuatro años y medio de la aplicación del Procede. A excepción de Oaxaca, Yucatán, Baja California, Nayarit, Hidalgo, Guanajuato, Veracruz, Jalisco, Michoacán, Guerrero, Chiapas y el Distrito Federal, el resto de entidades federativas registraron más del $50 \%$ de sus ejidos titulados para 1998. Los estados que presentaron mayor porcentaje de certificación fueron aquellos de menor extensión territorial, motivo por el cual, el porcentaje nacional de hectáreas documentadas resultan menor (Zepeda, 1998).

En 1998, Colima ya tenía certificados 134 ejidos de los 152 registrados y que poseen 225108,2 hectáreas de la superficie colimense que representan el $68 \%$, por lo que se convirtió en el segundo con mayor porcentaje de predios ejidales titulados. En el municipio de Manzanillo, el proceso de certificación se presentó de manera inmediata $\mathrm{y}$, a excepción de Tapeixtles, todos los ejidos que se proyectaron para proveer de suelo para la explotación minera e infraestructura portuaria, la industrial y el turismo, se integraron durante los primeros quince meses de su puesta en marcha, entre ellos Campos (Registro Agrario Nacional, 2013).

Las evidencias de la política aplicada que presentan Toledo (1994) y Concheiro y Diego (2003) muestran el acceso y apropiación de grandes extensiones territoriales que desertifican, contaminan el entorno natural y construyen escenarios propicios para una mayor inversión nacional y extranjera, a expensas del bienestar social y desarrollo rural. Con los títulos de propiedad y certificados parcelarios la compra-venta de tierras se 'legalizó', y, de esta manera, se intensificó su mercado en Manzanillo. A continuación, nos referimos especialmente a Campos.

\section{Mercado de tierras en el ejido de Campos, Manzanillo}

El ejido de Campos se localiza en el sudeste de la costa de Manzanillo, Colima, en las coordenadas geográficas $19^{\circ} 01.472 \mathrm{~N}$ y $104^{\circ} 19.89$ W. Se fundó en 1931 y tres años más tarde recibió su primera dotación de 959 hectáreas: 205 de humedad, 36 de área de arena, 114 de temporal y 604 cerril. En 1946, de manera extralegal se frustró la entrega de 300 hectáreas y, finalmente, en 1959 se adjudicó una ampliación por 1344 hectáreas: 68 de temporal y 1276 cerril (Registro Agrario Nacional, 2013). La primera dotación de tierra, corresponde al 
territorio ubicado sobre una franja costera entre el océano Pacífico y la laguna de $\mathrm{Cu}$ yutlán, mientras que la segunda extensión colinda hacia el norte con el mismo cuerpo de agua y terrenos ganados al ecosistema, con el ejido de El Colomo y La Arena y con la zona centro de la ciudad.

A pesar de no estar permitida legalmente, antes de la reforma al 27 constitucional, la venta de tierras ejidales en Campos, como seguramente en todo el país, era una práctica común. Por el ejemplo, el caso de Armín Núñez Meza, quien relata la forma cómo se convirtió en ejidatario: “...yo nací en 1935 y me hice ejidatario en 1963. Yo me hice de seis hectáreas que compré, el ejido no me las dio porque ya todo estaba repartido, yo le compré a una señora que quedó viuda, se fue a Guadalajara, me vendió su derecho de ejidatario y de ahí en adelante seguí" (Entrevista del autor a Armín Núñez Meza, Ejido de Campos, Manzanillo, Colima, 28 de febrero de 2013).

A partir de este momento, el líder campesino manzanillense continuó la compra de tierras en los ejidos de Campos y Colomos y La Arena. Más tarde, una vez que comenzó a operar la central termoeléctrica, uno de sus predios se convertiría en su nuevo hogar y en la última década sería uno de los ejidatarios que junto con Armida Núñez García $^{2}$ y su hija, vendieron suelo en mayor proporción para instalar la gasera Zeta y la planta regasificadora. Padre e hija sumaron 22 y 18 hectáreas, respectivamente, para el segundo proyecto.

Otro caso fue el de Rosendo Topete Zepeda. Según su hijo, Guillermo Topete
Palomera, ${ }^{3}$ actual representante ejidal de Campos:

“... en aquel tiempo mi papá recibió un derecho ejidal de un señor que lo quería pasar y estaba buscando a quien. En ese entonces se cedían los derechos nada más, no se permitían las ventas. Después, mi papá en vida decide pasarlo y me lo dejó a mí, entonces de ese modo es que yo llego a ser ejidatario (Entrevista con Guillermo Topete Palomera, zona Centro de Manzanillo, 27 de agosto de 2012).

Cuando por primera vez los ejidatarios escucharon hablar acerca del precio que podría alcanzar sus tierras, creyeron que se trataba de una broma. Fue en 1994, año en que a nivel nacional se vivía un periodo de modificaciones en la estructura ejidal producto de la adopción de políticas neoliberales, y en Manzanillo, particularmente en Campos, se comenzaba a 'preparar el terreno’ para la ejecución de los actuales proyectos. Durante una reunión celebrada con los ejidatarios de Campos, se dio a conocer que sus tierras en poco tiempo valdrían oro, con ellas se harían millonarios y quienes tuvieran los medios económicos compraran en otro sitio para construir sus viviendas, porque en un futuro este lugar ya no podría ser habitado.

Las palabras fueron juzgadas sin sentido por los ejidatarios, ¿cómo esas tierras que ya no generaban ganancias agrícolas para los ejidatarios valdrían tanto que se convertirían en millonarios? En ese momento, las expectativas del campesinado eran continuar con la actividad mediante el apoyo gu-
2 Ejidataria en Campos. Profesora (1976-2007), directora de la Unidad de Servicios Educativos de Manzanillo (2007-2009), representante del comisariado ejidal de Campos (2000-2003 y 2006-2009), presidenta de la Confederación Nacional Campesina (2001-2003), diputada local (2009-2012) y regidora del ayuntamiento de Manzanillo (2012-2015). Todos los cargos como integrante del PRI.

${ }^{3}$ Ejidatario en Campos. Representante del comisariado ejidal de Campos (2003-2006y 2009-2012) y presidente de la Confederación Nacional Campesina (2006-2009).

territarias 30

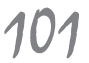


${ }^{4}$ Ejidatario de Campos, Manzanillo comprador de tierras a partir de 1994. En la actualidad es miembro de la Agrupación Ciudadana de Manzanillo (Aciman), de la cual, durante el periodo del 2011-2012, fue presidente.

${ }^{5}$ Ejidatario en Campos y El Colomo y La Arena. Representante del comisariado ejidal (1997-2000) y actualmente presidente de la Asociación de Productores de Coco del Estado de Colima e inspector ganadero en la región.

${ }^{6}$ Presidente Municipal de Tecomán (1998-2000),gobernador del Estado de Colima (2004-2005), diputado local en dos ocasiones, secretario general y presidente del Congreso del Estado en cuatro ocasionesy presidente del Comité Directivo Estatal del PRI. Todos los cargos afiliados al partido político antes mencionado.

${ }^{7}$ Ubicada de cara al Océano Pacífico sobre franja costera del ejido de Campos en el kilómetro 3,5 de la carretera estatal Manzanillo-Colima, entre las coordenadas geográficas $104^{\circ} 16.50^{\prime}$ latitud, y longitud $19^{\circ} 00.52^{\prime}$ '. El suelo adquirió o se aprovechó para áreas verdes ( 8 ha), las esferas, edificios administrativos $y$ de control, estacionamiento (16 ha) y zona de amortiguamiento (26 ba). La operación básica consiste en la recepción

\section{territarios 30} 102 bernamental prometido una vez aplicado el Procede. La venta de sus parcelas no estaba pensada y no fueron informados acerca de los planes que se proyectaban para el lugar.

En poco tiempo, la interacción de cuatro factores propició un dinámico proceso de venta y renta de parcelas en Campos y sus alrededores: 1) proyección de territorio para proveer de suelo para la infraestructura portuaria e industrial; 2) los efectos sobre el campo fértil para la agricultura tras la caída de humo emitido por la central termoeléctrica; 3) la titulación de la propiedad y la certificación parcelaria de los ejidatarios, así como 4) la ausencia de programas de apoyo para el agro.

En un primer momento, la compraventa de tierras se presentó al interior del ejido. Con base en los datos encontrados en el Acta de Asamblea General de Ejidatarios de Campos, Manzanillo, Colima, podemos dar cuenta de tres personas que adquirieron o ampliaron sus propiedades a partir de la aplicación del Procede. El primero de ellos es Margarito Tovar Laurel, ${ }^{4}$ un conocido personaje en el medio político manzanillense que comenzó a comprar tierras en el ejido de Campos entre los años de 1994 y 2000, para convertirse en ejidatario. Toribio Cruz Justo Rosales ${ }^{5}$ y Armida Núñez García, ambos comisarios ejidales en distintos momentos después de 1994. Seguramente, estos no fueron los únicos casos que se presentaron, pero son interesantes por estar vinculados al medio político local y haber vendido y contribuido en la compra venta para la instalación de los nuevos proyectos.
Las adquisiciones fueron realizadas por algunos ejidatarios locales que contaban con información privilegiada sobre la proyección industrial del ejido, e hicieron uso de sus conocimientos actuando de manera anticipada al resto de la población y, de ese modo, incrementar sus propiedades a partir de precios menores. En un segundo momento, la compra-venta de tierras se realizó al exterior del ejido. Empresas locales y regionales de bienes raíces, adquirieron un número importante de hectáreas para su posterior mercadeo a mayor coste al adquirido - ejercicio que hasta la actualidad continúa-. Sobre esta temática se prioriza a continuación.

\section{La compra-venta de tierras al interior del ejido}

Mientras la noticia de la posible instalación de una planta regasificadora en la costa de Colima tomaba fuerza, el 6 de septiembre del año 2004, ante la sorpresa de la población de Manzanillo, el entonces gobernador del Estado Gustavo Alberto Vázquez Montes $^{6}$ colocó la primera piedra para el establecimiento de 20 globos de almacenamiento de gas licuado de petróleo $(\mathrm{LP})^{7}$ propiedad de la empresa privada de capital mexicano, Grupo Zeta Gas del Pacífico S. A. de C. V. ${ }^{8}$ Su importancia radica en que fue la primera industria instalada en la zona después de la nueva ley agraria de 1992 y el Procede. Con ella se acentuó el cambió en el uso y aprovechamiento del suelo agrícola al industrial de alto impacto, marcando la continuación de un proceso caracterizado 
por fuerte presencia industrial que cambió el entorno rural de Campos.

Para su instalación fueron adquiridas aproximadamente 50 hectáreas de tierra que eran aprovechadas como cocotales y huertas de mango, limón y ciruela. En las negociaciones, los integrantes del comisariado ejidal fungieron como enlace entre el comprador y el vendedor, mientras que los grupos inmobiliarios resultaron fundamentales, convenciendo a los ejidatarios de vender sus tierras a precios que les permitiera beneficiarse con un porcentaje de la cifra acordado previamente con la empresa gasera, más el $6 \%$ que cada ejidatario otorgó del total de la cifra pactada. De este modo, entre conversaciones y entrevistas con los informantes clave apareció el nombre de Enrique Fernández Ibáñez, un empresario manzanillense en el ramo de bienes raíces.

A partir de las negociaciones para la construcción de la gasera Zeta, en el ejido de Campos comenzó un intenso mercado de tierras con grupos inmobiliarios que, hasta la actualidad, se puede intuir en la 'publicidad que anuncia la venta de tierras' y otros (ver figuras 1 y 2). Otro de los efectos de este proyecto gasero, fue que el precio acordado en la negociación, marcó el punto de referencia para catapultar el precio de los terrenos para los posteriores proyectos.

\section{La compra-venta de tierras al exterior del ejido}

La regasificadora consiste en dos tanques de almacenamiento de 150000 metros cúbicos de gas cada uno, con la posibilidad de
Figura 1. Mercado de tierras en el ejido de Campos, un negocio inmobiliario ( $\mathrm{km} 2$, carretera Campos-Manzanillo)

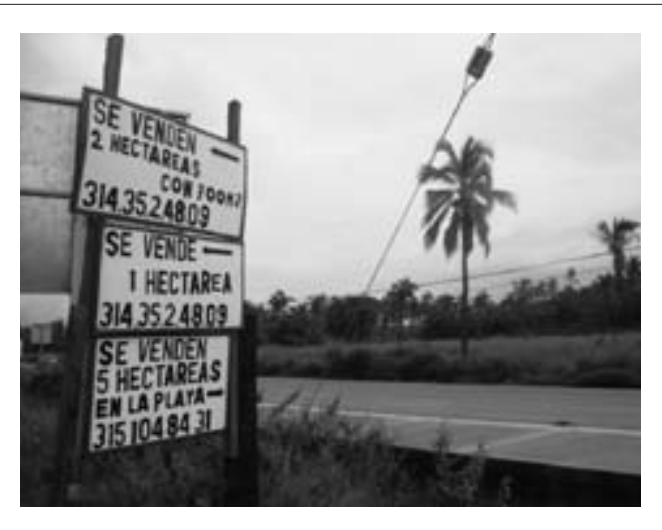

Archivo personal de Javier Verduzco. 22 de abril del 2013

Figura 2. La oferta de tierras, una demanda industrial en Campos (km. 4 carretera Campos-Manzanillo)

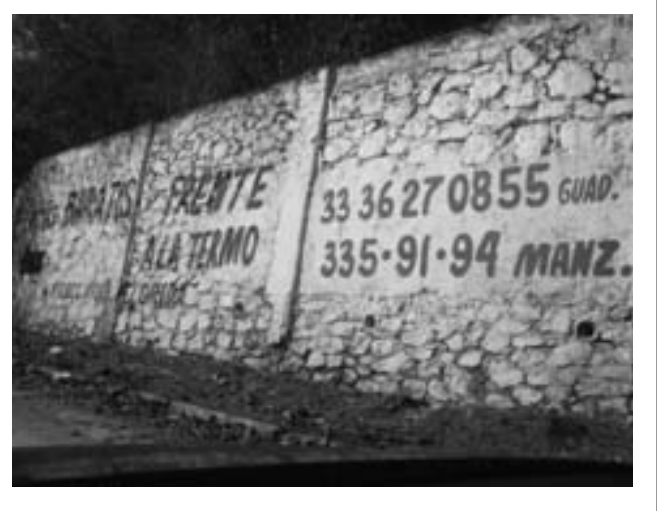

Archivo fotográfico de Javier Verduzco. 22 de abril del 2013.

construir dos unidades más. La concesión para construir la obra, recibir, almacenar, procesar y entregar el gas está a cargo del consorcio asiático Terminal KMS de GNL, S. de R. L. de C. V., conformado por la del gas transportado por medio de tanques hasta la costa colimense, en donde se almacena en las esferas a una temperatura de $0^{\circ} \mathrm{C}$ y presión de $5 \mathrm{~kg} / \mathrm{cm}^{2}$, posteriormente se bombea hacia los auto-tanques para su llenado y la distribución en los estados de la región occidente del pais (Secretaria de Medio Ambiente y Recursos Naturales, 2004, p. 9).

${ }^{8}$ El Grupo Zeta Gas del Pacifico $S$. A. de C. V. es una empresa privada de capital mexicano, que además de la planta en la costa colimense, cuenta con otrastres terminales maritimas en el continente americano: Ensenada, Baja California en México, el municipio guatemalteco de Amatitlán y el distrito de Miraflores, provincia de Lima, en Peru. En conjunto, almacena más de 109000 toneladas de gas LP que es transportado desde Sudamérica, Europa y África para comercializarse en el territorio mexicano. Dentro de sus clientes principales para el abasto del combustible energético se encuentra Petróleos Mexicanos (Pemex). En Manzanillo, en total puede almacenar 45000 toneladas por mes, saliendo por dia en promedio 40 auto tanques con capacidad por unidad de 4 a 24 mil litros cada una, para su distribución en Colima, Jalisco, Aguascalientes, Zacatecasy $\Rightarrow$

territarios 30

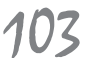

Mercado de tierras en un ejido mexicano: el caso de Campos, en Manzanillo, Colima, 1994-2013 
Guanajuato (Secretaría de Medio Ambiente y Recursos Naturales, 2004, p. 15).

territarias 30 104 empresa transnacional coreana Korea Gas (Kogas) y las japonesas Mitsui y Samsung C\&T. Mientras que el combustible en estado líquido transportado vía marítima desde Perú, lo realiza la española Repsol Comercializadora de Gas S. A. Cabe señalar que la infraestructura gasera instalada en Campos es clave en los proyectos energéticos del Estado mexicano, ya que con su conexión con el Sistema Nacional de Gasoductos asegura el suministro industrial, comercial, doméstico y energético en el centro y occidente del país.

La compra-venta de los predios para la regasificadora se presentó en un ambiente de controversias económicas entre la Comisión Federal de Electricidad (CFE) como promotor y algunos propietarios. A diferencia de la gasera Zeta, los representantes ejidales jugaron un papel importante en los acuerdos que se presentaron al ser contacto directo en las negociaciones. En una entrevista solicitada a Armida Núñez García, dirigente ejidal de Campos, para hablar acerca de su participación en la venta de tierras para instalar el proyecto de la regasificadora, a pregunta directa su respuesta fue la siguiente:

(...) sí, colaboramos con la CFE para que se instalara la regasificadora en Campos. Yo participé en alguna parte de las negociaciones y otra le tocó al siguiente presidente del ejido, Memo Topete, pero fui parte de la negociación. Yo facilité de alguna manera las tierras donde se instaló la regasificadora. No fue nada fácil porque hay gente que de verdad es campesina de corazón que nació campe- sina y que quieren, trabajan y aman su tierra, el campo es su vida. Hay otros campesinos que yo digo son campesinos light, que ya compraron la tierra y que esos más bien solo quieren hacer negocio, pero los campesinos de verdad para ellos no fue fácil. Decirte que aman la tierra, pero también la necesidad al ver que sus parcelas ya no producían lo necesario los hizo ver y negociar con la CFE. (...) La CFE primeramente nos buscó a nosotros, a los integrantes del comisariado, presidente, secretario y tesorero. Entonces, yo, tu servidora era la presidente y, por supuesto, fueron a decirme cuales parcelas necesitaban. Entonces nosotros ya les dijimos quienes eran los propietarios, fuimos el enlace con ellos y después de varias reuniones, porque no fue una sola reunión, varias reuniones, varias negociaciones porque déjame decirte que también la CFE quería darles cualquier cosa. Tú bien sabes que la gente piensa que porque son campesinos, ejidatarios, gente del campo, humilde, noble nos pueden hacer lo que ellos quieren, pero la verdad no fue nada fácil la negociación, pero finalmente se dio. Yo creo que vieron la necesidad que tenían de terrenos y la firmeza de los ejidatarios hizo que pagaran lo que ellos (ejidatarios) pidieron (Entrevista con Armida Núñez García, Zona centro, Manzanillo, 27 de agosto de 2012).

Para la construcción, fueron adquiridas 120 hectáreas de tierra ejidal aprovechadas como huertas de coco (Comisión Federal de Eectricidad, 2013). Fueron trece los campesinos que aceptaron la venta de sus propiedades, entre ellos Francisco Calle- 
ros López, José Arteaga Valdez, Rosendo Topete, Florencio Campos Nava, César Sandoval García, Margarito Tovar Laurel, Vicente Benavides García y la misma entrevistada.

Cabe aclarar que la profesora Núñez no se autoseñaló, porque tal vez el tema resulta incómodo debido a las fuertes críticas que ha recibido de la población manzanillense.

$\mathrm{Al}$ contrastar los nombres mencionados en el párrafo anterior, con la relación de ejidatarios que recibieron los derechos agrarios legalmente reconocidos en el Acta de Asamblea General de Ejidatarios de Campos, Manzanillo, con fecha del día 3 de noviembre de 1994 (Registro Agrario Nacional, 2013), hay indicios de que Margarito Tovar Laurel y Armida Núñez lograron adquirir los predios que después vendieron a mayor precio, para que la KMS construyera la planta regasificadora.

Ejidatarios que no aceptaron vender, afirman que el precio no era correcto. Tal es el caso de Felipe López Rodríguez, quien sostiene que "la cifra no estaba bien evaluada porque la CFE desde la Ciudad de México con un tabulador precisó la cantidad por hectárea a pagarse sin dar a conocer los datos". Sin embargo, al poco tiempo de negarse, decidió acceder a la oferta que 'alguien más' le hizo, ya que esta representó una mayor cantidad. Su parcela conserva las palmeras de coco, pero ahora el fruto no se comercializa como frutal, sino como materia para la producción de aceite de coco.

Otro caso fue Justo Toribio, quien vendió tres hectáreas para la gasera en el año 2004, pero para la construcción de la regasificadora no aceptó luego. El motivo por el que tomó esa decisión fue debido a la forma como los intermediarios negociaron a su favor. Previo a los convenios con los ejidatarios, la CFE asignó a los mediadores un presupuesto para que negociaran con los propietarios de las parcelas ejidales. Como pago por su colaboración recibieron el $20 \%$ del monto otorgado, aunque sus ganancias incrementaron, ya que el precio acordado por las propiedades resultó menor al asignado por la paraestatal. Aunado a esto, por su labor a los ejidatarios también les cobraron el $6 \%$ del precio de las tierras. Por este motivo, la postura del campesino fue firme y asegura que no cambiará: "yo no vendo a menos que me lleguen al precio, cuando alguien llegue a lo que pido nos sentamos a platicar" (Conversación informal con Justo Toribio Cruz, Ejido de Campos, Manzanillo, 1 de marzo de 2013).

El campesino relata que la misma persona que fungió como intermediario en las negociaciones para el Grupo Z, en varias ocasiones quiso tratar de nuevo aumentando el precio de la venta, incluso, personal de la CFE habló con él porque el proyecto ya contemplaba su predio como parte del polígono de la planta regasificadora y de no comprar tendrían que modificarse los planos. La respuesta a ambos fue negativa, "no llegaban al precio", sin embargo, tampoco los interesados mostraron mayor empeño por ceder a la petición de Justo Toribio. Finalmente, el proyecto se construyó sin considerar las cinco hectáreas no adquiridas, aunque, el daño a los predios fue grave por ser colindantes a la regasificadora. territarias 30

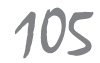


Luego de la instalación de las esferas de la gasera Zeta y la planta regasificadora se transformó el suelo antes usado y aprovechado para la actividad agrícola. Según Justo Toribio, en Campos había poco más de 200 hectáreas de palma de coco, pero si consideramos las 50 hectáreas del primer proyecto y las 150 del segundo, el área para la producción frutal o agroindustrial — aceite de $\mathrm{Coco}$ - está por desaparecer. De hecho, la parcela del entrevistado es de las pocas que siguen generando ingresos con la actividad agrícola.

Figura 3. Cambio en el uso del suelo, antes agrícola y ahora industria de alto impacto (km. 1 carretera Campos-Manzanillo)

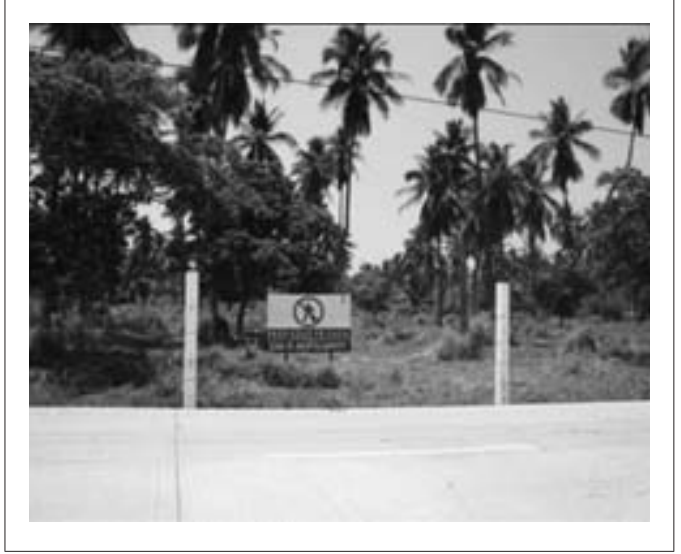

Archivo personal de Javier Verduzco. 22 de abril del 2013.

\section{Conclusiones}

En el discurso, la planificación del territorio apunta hacia el uso y aprovechamiento del suelo de manera ordenada, y considerando los aspectos sociales y las condiciones naturales, de manera que los resultados obtenidos sean equitativos para la población y sin alterar el entorno. Sin embargo, la zonificación del territorio manzanillense priorizó la asignación de suelo para el desarrollo de actividades como la minería, la portuaria, el turismo y la industria energética, en detrimento de la agricultura. De esta manera, el Plan de Desarrollo Metropolitano de 1975 donde se plasmó dicha estrategia política, resultó un instrumento de poder puesto en marcha por el Estado, cuyos resultados muestran una forma de control social y económico, así como la apropiación del territorio, en beneficio de los grupos de inversionistas tanto nacionales como extranjeros.

Para la construcción de los proyectos gaseros en Manzanillo fueron necesarias grandes porciones de tierra que en mayor porción fueron tomadas del suelo agrícola. Sin embargo, como consecuencia se deforestó y contaminó el entorno natural, lo que impactó las tradicionales fuentes de empleo agropecuarias de la población. De esta forma, el ejido de Campos se enlazó de manera directa con la economía global, como parte de la estrategia mercantil tanto nacional, como mundial.

La reforma al artículo 27 constitucional y la aplicación del Procede a nivel nacional, modificaron el régimen de propiedad al convertir a los ejidatarios en propietarios de sus tierras y, con ello, les posibilitaron vender o rentar sus parcelas. Así, los ejidatarios de Campos lograron vender 'legalmente' sus propiedades. De este modo, aquel sitio rico en recursos naturales, catalogado por sus pobladores como 'un vergel agrícola', 
pasó a considerarse como un recinto industrial de alto impacto y estratégico a nivel federal e internacional.

En principio, el territorio de Campos estuvo condicionado por factores físicos que determinaban su aprovechamiento. De este modo, el entorno natural ejerció peso para que se desarrollaran actividades agrícolas. Sin embargo, con las modificaciones ocasionadas en el medio, se presentó un proceso de transformación y acondicionamiento de la tierra por parte de los grupos que de manera distinta se han apropiado del territorio, sometiéndolo a nuevos modos de usufructo no rural.

La presión industrial sobre el campo agrícola que ha provocado la mala calidad de la tierra, contaminada por la caída de humo con alto contenido de óxidos de azufre $\left(\mathrm{SO}_{2}\right)$, óxidos de nitrógeno $\left(\mathrm{NO}_{\mathrm{X}}\right)$, partículas suspendidas, fue un factor clave en la toma de decisión por parte de los ejidatarios de vender sus parcelas, pues ya no veían en el campo una inversión remunerable. Además, ante la magnitud del proyecto e intenciones de las autoridades por imponer la inversión y las presiones por expropiar a los propietarios de estos terrenos no les quedó otra opción que aceptar la venta y, con esto, obtener ingresos antes de que fueran expropiados.

Con los datos presentados hasta el momento, planteamos el escenario de promoción capitalista situado en Campos, Manzanillo durante la década de los setenta y su proyección económica hacia el año 2000. A la vez, se muestra la magnitud de los proyectos transnacionales colmados de intere- ses externos al alcance local y a la planeación de su territorio. Por lo tanto, el territorio geográfico del ejido de Campos, significó un sitio importante para las expectativas de crecimiento y desarrollo municipal, estatal y nacional. En contraparte, para el sector agrícola como actividad económica principal, representó luchar contra lo inevitable.

\section{Referencias}

Comisión Federal de Electricidad. (2013). Brecha de futuros. Proyecto Integral Manzanillo. México, D. F.: Autor.

Comisión Federal de Electricidad. (s. f.). Central termoeléctrica Manuel Álvarez Manzanillo, Colima. México, D. F.: Autor.

Concheiro, L. y Diego, R. (2003). Una perspectiva campesina del mercado de tierras ejidales: siete estudios de caso. México, D. F.: Casa Juan Pablos.

Ezquerra, J. L. (2006). Historia y futuro del desarrollo turístico y portuario del litoral en Manzanillo, Colima. Colima: Coedi Mex S. A. de C.V.

Godau, R. (1982). Estado y acero. Historia politica de las Truchas. México, D. F.: El Colegio de México.

Morett, J. C. (2003). Reforma agraria: del latifundio al neoliberalismo. México, D. F.: Plaza y Valdés.

Registro Agrario Nacional. (2013). Padróne historial de núcleos agrarios. Recuperado de http://phina.ran.gob.mx/phina2/ Sessiones

Secretaría del Patrimonio Nacional. (1975). Plan Director de Desarrollo Metropo- territarias 30 107 
litano de Manzanillo. México, D. F.: Cervantes Asociados, S. A.

Toledo, V. M. (1994). La Ecologia, Chiapas y el Articulo 27. México, D. F.: Ediciones $5^{\circ}$ sol.

Yiftachel, O. (1998). Planning and Social Control: Exploring the Dark Side. Jour- nal of Planning Literature, 12(2), 395406.

Zepeda, G. (1998). Cuatro años de Procede: avances y desafíos en la definición de derechos agrarios en México. México, D. F.: Centro de Investigación para el Desarrollo A. C. 